\title{
A comparison of oxytocin and carboprost tromethamine in the prevention of postpartum hemorrhage in high-risk patients undergoing cesarean delivery
}

\author{
JING BAI, QIAN SUN and HUI ZHAI
}

Department of Gynecology and Obstetrics, Jinan Maternity and Child Care Hospital, Jinan, Shandong 250001, P.R. China

Received June 20, 2013; Accepted October 17, 2013

DOI: 10.3892/etm.2013.1379

\begin{abstract}
The aim of this study was to compare carboprost with oxytocin for the prevention of postpartum hemorrhage $(\mathrm{PPH})$ in females with a high risk of PPH undergoing cesarean delivery. Patients were randomly divided into three groups that received different uterotonics (oxytocin, carboprost and oxytocin plus carboprost) during cesarean section, following the delivery of the infant. A total of 117 females (age range, 19-40 years) at 35-40 weeks gestation who delivered by cesarean between December, 2010 and May, 2012 were included in this study. There were 29 cases of twins, 12 cases of polyhydramnios, 23 cases of placenta previa and 53 cases of fetal macrosomia. There were 37 patients in the oxytocin group, 36 in the carboprost group and 44 in the oxytocin plus carboprost group. No significant differences were identified in maternal age, gravidity/parity, gestational age and reason for cesarean delivery between the three groups. The median blood loss in the oxytocin, carboprost and oxytocin plus carboprost groups was 610, 438 and $520 \mathrm{ml}$, respectively. The blood loss in the carboprost group was significantly lower than that in the oxytocin and oxytocin plus carboprost groups (both $\mathrm{P}<0.05$ ). Vomiting occurred in eight patients from the carboprost group, two from the oxytocin group and two from the oxytocin plus carboprost group $(\mathrm{P}=0.036)$. Carboprost was more effective than oxytocin in preventing $\mathrm{PPH}$ in high-risk patients undergoing cesarean delivery.
\end{abstract}

Correspondence to: Dr Jing Bai, Department of Gynecology and Obstetrics, Jinan Maternity and Child Care Hospital, 2 Jianguo Xiaojing 3rd Road, Shizhong, Jinan, Shandong 250001, P.R. China

E-mail: jingbai123@yeah.net

Abbreviations: $\mathrm{PPH}$, postpartum hemorrhage

Key words: carboprost, oxytocin, postpartum hemorrhage, third stage of labor

\section{Introduction}

Postpartum hemorrhage (PPH) refers to $>500 \mathrm{ml}$ blood loss within $24 \mathrm{~h}$ following vaginal delivery, $>1,000 \mathrm{ml}$ following cesarean delivery, or the requirement for a blood transfusion within $24 \mathrm{~h}$ of delivery $(1,2)$. PPH is reported to occur in $~ 5 \%$ of all deliveries, and the risk is significantly greater with cesarean delivery than vaginal delivery $(3,4)$. In China, PPH is the most common serious obstetric complication and the leading cause of maternal mortality, accounting for $49.9 \%$ of maternal deaths (5). The leading cause of PPH is uterine atony, followed by retained placenta and injury to the genital tract $(1,3)$. Risk factors for PPH include fetal macrosomy, prolonged labor, multiple pregnancies, polyhydramnios, uterine myoma, placenta previa, grand multiparity and uterine infection $(1,3)$.

The majority of maternal deaths due to PPH may be avoided, and the key lies in early diagnosis and proper treatment. However, PPH is one of the most challenging complications faced by clinicians. Active management of the third stage of labor includes the administration of uterotonic agents following the cesarean section or during the third stage of labor for vaginal delivery, and studies have shown that it may reduce the incidence of PPH (1,6-9). Oxytocin is the most commonly used uterotonic agent for the prevention of $\mathrm{PPH}$, and has been demonstrated to reduce blood loss following delivery $(1,8)$. However, oxytocin has a half-life of $<10 \mathrm{~min}$ and thus must be administered by continuous intravenous infusion (10). Furthermore, saturation of uterine receptors may occur, and excessive dosages are capable of producing water toxicity due to its antidiuretic effect (10). Other uterotonic agents have been studied, and have been shown to reduce PPH, including carbetocin, a long-acting synthetic oxytocin analogue, ergot alkaloids (such as ergonovine, syntometrine) and prostaglandins (such as misoprostol and carboprost) (11-17).

Carboprost tromethamine (Hemabate) is the synthetic 15-methyl analogue of prostaglandin $\mathrm{F}_{2 \alpha}$, and has been reported to be $84-96 \%$ effective in the treatment of persistent hemorrhage due to uterine atony (18). However, since its introduction, there have been few studies of its effectiveness for the prevention and treatment of $\mathrm{PPH}$, and only one specifically examining its use following cesarean delivery $(16,17,19-21)$.

The purpose of this study was to compare carboprost with oxytocin for the prevention of PPH in high-risk females undergoing cesarean delivery. 
Table I. Patient demographic data.

\begin{tabular}{lccc}
\hline Variables & $\begin{array}{c}\text { Oxytocin group } \\
(\mathrm{n}=37)\end{array}$ & $\begin{array}{c}\text { Carboprost group } \\
(\mathrm{n}=36)\end{array}$ & $\begin{array}{c}\text { Oxytocin }+ \text { carboprost group } \\
(\mathrm{n}=44)\end{array}$ \\
\hline Age (years) & $28.65 \pm 4.77$ & $27.92 \pm 4.29$ & $27.05 \pm 3.54$ \\
Reason for cesarean delivery ${ }^{\mathrm{b}}$ & $11(29.7)$ & $7(19.4)$ & $0.230^{\mathrm{d}}$ \\
Twin pregnancy & $3(8.1)$ & $5(13.9)$ & $0.928^{\mathrm{e}}$ \\
Hydramnios & $6(16.2)$ & $7(19.4)$ & $4(9.1)$ \\
Placenta previa & $17(45.9)$ & $17(47.2)$ & $10(22.7)$ \\
Macrosomia $_{\text {Gestational age (weeks) }}{ }^{\mathrm{a}}$ & $37.99 \pm 1.22$ & $37.37 \pm 1.33$ & $37.99 \pm 1.39$ \\
Gravida $^{\mathrm{c}}$ & $2(1-6)$ & $2(1-5)$ & $2(1-4)$ \\
Para $^{\mathrm{c}}$ & $1(1-3)$ & $1(1-3)$ & $1(1-3)$ \\
\hline
\end{tabular}

Data are presented as the ${ }^{\mathrm{a}}$ mean $\pm \mathrm{SD}$; ${ }^{\mathrm{b}}$ number (percentage); and ${ }^{\mathrm{c}}$ median (range). P-values are from ${ }^{\mathrm{d}}$ analysis of variance (ANOVA); ${ }^{\mathrm{e}}$ Fisher's exact test; and ${ }^{\mathrm{f}}$ Kruskal-Wallis test.

\section{Patients and methods}

Patients. Pregnant females at a high risk of PPH who were scheduled to undergo a cesarean section at the Jinan Maternity and Child Care Hospital (Jinan, China) between December, 2010 and May, 2012 were included in this study. Patients with coagulation disorders or contraindications for receiving prostaglandin drugs were excluded from the study. The patients were randomly divided into three groups and received different uterotonics (oxytocin, carboprost and oxytocin plus carboprost) during cesarean section, following the delivery of the infant. This study was approved by the Institutional Review Board of the Jinan Maternity and Child Care Hospital, and all patients provided written informed consent for participation in the study.

Interventions. In the oxytocin group, patients received a myometrial injection of 20 units oxytocin (Shanghai Harvest Pharmaceutical Co., Ltd., Shanghai, China) during the cesarean section, immediately following the delivery of the infant, and subsequently a continuous intravenous infusion of 20 units oxytocin diluted in 1,000 ml saline or Ringer's solution. In the carboprost group, patients received a myometrial injection of $0.25 \mathrm{mg}$ carboprost tromethamine (Pharmacia \& Upjohn Company, Kalamazoo, MI, USA) during the cesarean section, immediately following the delivery of the infant. The injection was repeated every $15 \mathrm{~min}$, as required, until a maximum total dose of $2 \mathrm{mg}$ had been administered. In the oxytocin plus carboprost tromethamine group, patients received a myometrial injection of $0.25 \mathrm{mg}$ carboprost tromethamine and continuous intravenous infusion of 20 units oxytocin diluted in 1,000 $\mathrm{ml}$ saline or Ringer's solution during the cesarean section, immediately following the delivery of the infant.

In cases in which uterine bleeding was not able to be effectively controlled by the aforementioned methods and the blood loss was $\geq 1,000 \mathrm{ml}$, other methods of control, including the administration of additional uterotonic agents, uterine artery ligation, uterine gauze packing or blood transfusions, were used.

Data recorded and compared included the volume of blood lost during surgery and within $2 \mathrm{~h}$ of surgery, preoperative and postoperative hemoglobin levels, and the other methods used to control bleeding, if required.

Statistical analysis. Continuous variables are presented as the mean \pm standard deviation or median with range, depending on the normality of the data distribution. Categorical variables are expressed by frequencies and percentages. The differences among the three groups were detected using analysis of variance (ANOVA) or a Kruskal-Wallis test for continuous variables, and using a Fisher's exact test for categorical variables, as appropriate. In addition, the differences prior to and following delivery were examined using the paired Student's t-test or Wilcoxon signed ranks test. For all analyses, a two-sided $\mathrm{P}<0.05$ was considered to indicate a statistically significant difference. Statistical analyses were performed using SPSS 15.0 statistical software (SPSS Inc., Chicago, IL, USA).

\section{Results}

Patients. A total of 117 females at increased risk of PPH who received a cesarean delivery between December, 2010 and May, 2012 were included in this study. The patients were between 19 and 40 years of age and 35 and 40 weeks gestation. There were 29 cases of twins, 12 cases of polyhydramnios, 23 cases of placenta previa and 53 cases of fetal macrosomia. There were 37 patients in the oxytocin group, 36 in the carboprost group and 44 in the oxytocin plus carboprost group. No significant differences were identified in maternal age, gravidity and parity, gestational age at delivery and reason for cesarean delivery among the three groups (all P $>0.05$, Table I).

Blood loss and interventions. Blood loss was $\geq 1,000 \mathrm{ml}$ in 13 patients from the oxytocin group, four patients from the carboprost group, and three patients from the oxytocin plus carboprost group. In the oxytocin group, the oxytocin dose was increased or other drugs were also administered in 12 cases, bilateral uterine artery ligation was performed in six cases, uterine gauze packing was adopted in two cases and a blood transfusion was performed in four cases (data not shown). 
Table II. Adverse events.

\begin{tabular}{|c|c|c|c|c|}
\hline Variables & $\begin{array}{l}\text { Oxytocin group } \\
\qquad(\mathrm{n}=37)\end{array}$ & $\begin{array}{l}\text { Carboprost group } \\
\qquad(\mathrm{n}=36)\end{array}$ & $\begin{array}{l}\text { Oxytocin + carboprost group } \\
\qquad(\mathrm{n}=44)\end{array}$ & P-value \\
\hline Nausea & $2(5.4)$ & $6(16.7)$ & $4(9.1)$ & 0.274 \\
\hline Vomiting & $2(5.4)$ & $8(22.2)^{\mathrm{a}}$ & $2(4.5)^{b}$ & $0.036^{\mathrm{c}}$ \\
\hline Fever & $2(5.4)$ & $3(8.3)$ & $0(0.0)$ & 0.096 \\
\hline Diarrhea & $0(0.0)$ & $1(2.8)$ & $1(2.3)$ & 0.758 \\
\hline Headache & $0(0.0)$ & $1(2.8)$ & $0(0.0)$ & 0.297 \\
\hline Elevated blood pressure & $0(0.0)$ & $4(11.1)$ & $2(4.5)$ & 0.113 \\
\hline
\end{tabular}

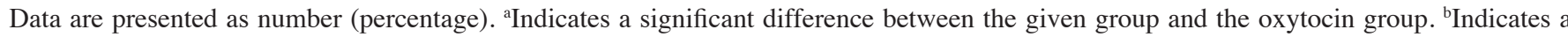
significant difference between the given group and carboprost group. 'Indicates a significant difference among the three groups.

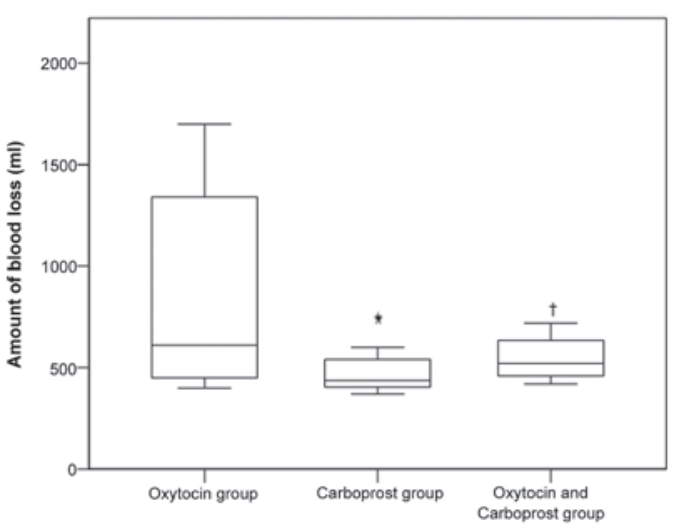

Figure 1. Primary outcome: Amount of blood loss. "Indicates a significant difference between the given group and the oxytocin group. Indicates a significant difference between the given group and the carboprost group.

In the carboprost group the dosage was increased or other drugs were also administered in three cases, bilateral uterine artery ligation was performed in three cases and uterine gauze packing was adopted in two cases. In the oxytocin plus carboprost group, the carboprost dose was increased or other drugs were also administered in two cases, bilateral uterine artery ligation was performed in two cases and uterine gauze packing was adopted in one case.

The median blood loss in the oxytocin, carboprost, and oxytocin plus carboprost groups was 610,438 and $520 \mathrm{ml}$, respectively (Fig. 1). The median blood loss in the carboprost group was significantly lower than that in the oxytocin and oxytocin plus carboprost groups (both $\mathrm{P}<0.05$ ). The change in hemoglobin levels prior to and following delivery in the three groups is shown in Fig. 2. In all three groups, the hemoglobin level following delivery was significantly lower than it had been prior to delivery (all $\mathrm{P}<0.01$, Fig. 2A). Furthermore, there was a significant difference in the reduction in hemoglobin levels among the three groups $(\mathrm{P}<0.001$, Fig. 2B). Patients in the carboprost and oxytocin plus carboprost groups had a significantly smaller reduction in hemoglobin levels compared with the oxytocin group.

Adverse events. The adverse events that occurred in the three groups are summarized in Table II. Nausea and vomiting were the most common adverse events. Vomiting occurred in
A

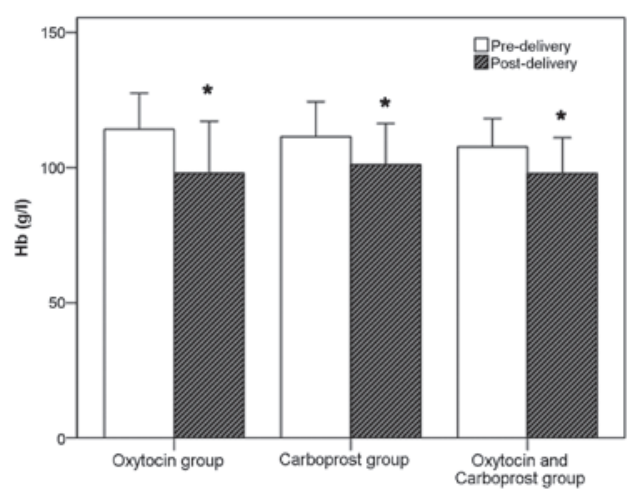

B

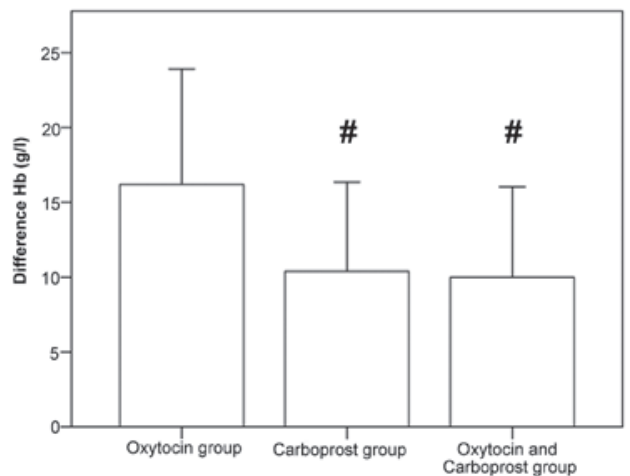

Figure 2. Secondary outcome: Difference in hemoglobin levels prior to and following delivery. (A) Pre- and post-delivery hemoglobin levels for oxytocin, carboprost, and combination of oxytocin and carboprost groups, separately. (B) Difference of hemoglobin levels from pre-delivery to post-delivery for oxytocin, carboprost, and combination of oxytocin and carboprost groups, separately. "Indicates a significant difference prior to and following delivery in each group." Indicates a significant difference between the given group and the oxytocin group.

eight $(22.2 \%)$ patients in the carboprost group, as compared with two $(5.4 \%)$ in the oxytocin group and two $(4.5 \%)$ in the oxytocin plus carboprost group, and the difference was statistically significant $(\mathrm{P}=0.036)$.

\section{Discussion}

The results of the present study demonstrated that carboprost was more effective at preventing PPH than oxytocin in patients at a high risk of PPH undergoing cesarean delivery. The side-effects observed in the three groups were similar, with 
the exception of vomiting, which was more common in the patients who received carboprost.

To date, PPH remains a leading cause of maternal morbidity and mortality in China, as well as in many underdeveloped countries $(2,5)$. The main causes of PPH are uterine atony, residual trophoblastic tissue, genital tract trauma and clotting disorders. Of these, uterine atony is the most common and is apparent in 70-90\% of all cases of PPH $(1,2)$. PPH within $2 \mathrm{~h}$ of delivery accounts for $\sim 90 \%$ of the total number of cases $(1,2)$.

Oxytocin is the most commonly used drug for the prevention and treatment of excessive bleeding following delivery (8). The most significant benefit of oxytocin is rapid action without causing elevated blood pressure or tetanic uterine contractions. Studies have demonstrated that the routine prophylactic use of oxytocin may reduce the need for additional uterotonics $(8,22)$. However, the use of oxytocin is limited by the dose. Myometrial oxytocin receptor saturation may affect its effectiveness, and excessive dosages may result in coronary artery contraction, hypotension and antidiuretic effect-induced water intoxication $(8,23)$. Therefore, other uterotonics may be required in patients at high-risk of $\mathrm{PPH}$. While it is clear that uterotonics are capable of reducing blood loss during the third stage of labor and preventing $\mathrm{PPH}$, the most effective uterotonic in in the case of cesarean versus vaginal delivery and in certain other circumstances has not been elucidated $(1,7)$.

Carboprost tromethamine is the synthetic 15-methyl analogue of prostaglandin $\mathrm{F}_{2 \alpha}$. It may be administered via intramuscular injection at a dose of $0.25 \mathrm{mg}$, and may be repeated every $15 \mathrm{~min}$ until a maximum total dose of $2 \mathrm{mg}$ has been administered (24). Carboprost has been reported to be $84-96 \%$ effective in the treatment of persistent hemorrhage due to uterine atony, and may avoid the need for surgical intervention (18). However, few studies have examined its use for the prevention of PPH. Vaid et al (16) compared prophylactic sublingual misoprostol, intramuscular methylergometrine and intramuscular carboprost for the active management of the third stage of labor, and observed that the three drugs were equally effective in the prevention of $\mathrm{PPH}$, although diarrhea was more common in the patients who received carboprost. In a similar study, Abdel-Aleem et al (19) compared carboprost and methylergometrine in 150 females who were randomly assigned to receive one of the two drugs, and observed that the duration of the third stage of labor and mean blood loss were significantly less in the carboprost group. Oleen and Mariano (20) reported that carboprost effectively controlled bleeding in 208 out of $237(87.8 \%)$ cases of PPH.

Carboprost may cause prostaglandin-like side-effects, including nausea, vomiting, diarrhea, headaches, hypertension and bronchial asthma caused by the contraction of smooth muscles (24). It may also act on the thermoregulatory center, increasing the basal body temperature (24). Patients may experience hot flashes, sweating and increased irritability. Lamont et al (17) compared carboprost and syntometrine for the prevention of $\mathrm{PPH}$ and revealed that although the two drugs were as effective in the prevention of PPH, diarrhea occurred in $21 \%$ of the patients who received carboprost, compared with only $0.8 \%$ of the patients who received syntometrine. Despite the aforementioned potential side-effects, serious side-effects are rare and self-limited (16). The present results demonstrated that vomiting was relatively common in the patients who received carboprost; however, it was readily managed.

There are limitations to the present study that should be considered. This was a single center study with a relatively small study group; thus, the results may not be generalizable to other patient populations.

In conclusion, the results of this study demonstrated that carboprost was more effective than oxytocin in preventing PPH in high-risk patients undergoing cesarean delivery. The drug was well-tolerated with minimal adverse effects. Carboprost may be considered to be suitable drug for the active management of the third stage of labor in this patient population.

\section{References}

1. Leduc D, Senikas V, Lalonde AB, et al: Active management of the third stage of labour: prevention and treatment of postpartum hemorrhage. J Obstet Gynaecol Can 31: 980-993, 2009.

2. World Health Organization: WHO recommendations for the prevention of postpartum haemorrhage. World Health Organisation: Department of Making Pregnancy Safer, Geneva, Switzerland, 2007.

3. Carroli G, Cuesta C, Abalos E and Gulmezoglu AM: Epidemiology of postpartum haemorrhage: a systematic review. Best Pract Res Clin Obstet Gynaecol 22: 999-1012, 2008.

4. Wedisinghe L, Macleod M and Murphy DJ: Use of oxytocin to prevent haemorrhage at caesarean section - a survey of practice in the United Kingdom. Eur J Obstet Gynecol Reprod Biol 137: 27-30, 2008.

5. Su Y, Xu Z and Jiang S (eds): Practical Obstetrics. 2nd edition. Shandong Science and Technology Press, Jinan, Shandong, China, pp486, 2004

6. Begley CM, Gyte GM, Devane D, McGuire W and Weeks A: Active versus expectant management for women in the third stage of labour. Cochrane Database Syst Rev 11: CD007412, 2011.

7. Gizzo S, Patrelli TS, Gangi SD, et al: Which uterotonic is better to prevent the postpartum hemorrhage? Latest news in terms of clinical efficacy, side effects, and contraindications: a systematic review. Reprod Sci 20: 1011 1019, 2013.

8. Roach MK, Abramovici A and Tita AT: Dose and duration of oxytocin to prevent postpartum hemorrhage: a review. Am J Perinatol: Dec 3, 2012 (Epub ahead of print).

9. Oladapo OT, Akinola OI, Fawole AO, et al: Active management of third stage of labor: evidence versus practice. Acta Obstet Gynecol Scand 88: 1252-1260, 2009.

10. Rath W: Prevention of postpartum haemorrhage with the oxytocin analogue carbetocin. Eur J Obstet Gynecol Reprod Biol 147: 15-20, 2009.

11. Higgins L, Mechery $\mathrm{J}$ and Tomlinson AJ: Does carbetocin for prevention of postpartum haemorrhage at caesarean section provide clinical or financial benefit compared with oxytocin? J Obstet Gynaecol 31: 732-739, 2011.

12. De Bonis M, Torricelli M, Leoni L, et al: Carbetocin versus oxytocin after caesarean section: similar efficacy but reduced pain perception in women with high risk of postpartum haemorrhage. J Matern Fetal Neonatal Med 25: 732-735, 2012.

13. Gibbins KJ, Albright CM and Rouse DJ: Postpartum hemorrhage in the developed world: whither misoprostol? Am J Obstet Gynecol 208: 181-183, 2013.

14. Cordovani D, Balki M, Farine D, et al: Carbetocin at elective Cesarean delivery: a randomized controlled trial to determine the effective dose. Can J Anaesth 59: 751-757, 2012.

15. Su LL, Chong YS and Samuel M: Carbetocin for preventing postpartum haemorrhage. Cochrane Database Syst Rev 4: CD005457, 2012.

16. Vaid A, Dadhwal V, Mittal S, et al: A randomized controlled trial of prophylactic sublingual misoprostol versus intramuscular methyl-ergometrine versus intramuscular 15-methyl PGF2alpha in active management of third stage of labor. Arch Gynecol Obstet 280: 893-897, 2009.

17. Lamont RF, Morgan DJ, Logue M and Gordon H: A prospective randomised trial to compare the efficacy and safety of hemabate and syntometrine for the prevention of primary postpartum haemorrhage. Prostaglandins Other Lipid Mediat 66: 203-210, 2001. 
18. Buttino L Jr and Garite TJ: The use of 15 methyl F2 alpha prostaglandin (Prostin 15M) for the control of postpartum hemorrhage. Am J Perinatol 3: 241-243, 1986.

19. Abdel-Aleem H, Abol-Oyoun EM, Moustafa SA, et al: Carboprost trometamol in the management of the third stage of labor. Int J Gynaecol Obstet 42: 247-250, 1993.

20. Oleen MA and Mariano JP: Controlling refractory atonic postpartum hemorrhage with Hemabate sterile solution. Am J Obstet Gynecol 162: 205-208, 1990.

21. Ezeh UO and Pearson M: The control of blood loss at cesarean section with intramyometrial prostaglandin F2 alpha analog versus intravenous synthetic oxytocin. Am J Obstet Gynecol 173: 353-354, 1995.
22. Nordström L, Fogelstam K, Fridman G, Larsson A and Rydhstroem H: Routine oxytocin in the third stage of labor: a placebo controlled randomized trial. Br J Obstet Gynecol 104: 781-786, 1997.

23. Güngördük K, Asicioglu O, Celikkol O, Olgac Y and Ark C: Use of additional oxytocin to reduce blood loss at elective caesarean section: A randomised control trial. Aust N Z J Obstet Gynaecol 50: 36-39, 2010

24. Carboprost [Package insert]. Kirkland. Quebec, Canada: Pfizer; 2004. 